\title{
Reduced incidence of maternal health conditions associated with the home-based newborn care intervention package in Rural Gadchiroli, India: a 13 years before - after comparison
}

\author{
Anand A Bang ${ }^{1}$, Abhay T Bang ${ }^{1}$, Rani Bang ${ }^{1}$, Mahesh Deshmukh¹, Kalindi Soni², Sanjay Baitule ${ }^{1}$ \\ 1 Society for Education, Action and Research in Community Health, Gadchiroli, Maharashtra, India, ${ }^{2}$ Pratham Education Foundation, Pratham \\ Institute for Literacy, Education \& Vocational Training, Mumbai, Maharashtra, India \\ Keywords: newborn, home-based care, maternal health, rural india \\ https://doi.org/10.29392/001c.30065
}

\section{Journal of Global Health Reports}

Vol. 5, 2021

\section{Background}

To evaluate the association between home-based neonatal care interventions and the incidence of maternal health conditions as well as to estimate the longitudinal trend of the incidence of maternal health conditions over 13 years in 39 villages of the field program area of the of home-based neonatal care from rural Gadchiroli, India.

\section{Methods}

This was a before-after comparative analysis of a program implemented in thirty-nine villages in Gadchiroli, India. The home-based newborn care interventions were incrementally introduced during the field trial (1995 - 1998) and continued as a service program until 2008. Over thirteen years (1995-2008), pregnant women were recruited and followed up from the seventh month of pregnancy to 28 days postpartum by trained female community health workers who made antenatal, natal and post-natal home visits, provided health education to mothers for behavior change, managed normal and sick neonates as well as encouraged seeking medical care when necessary. They recorded maternal symptoms and signs, which a physician supervisor verified. Based on these symptoms and signs, a computer algorithm diagnosed 20 different maternal health conditions. The incidence of these conditions in the first year (1995-96) was compared with the intervention's last two years (2006 - 2008).

\begin{abstract}
Result
The mean coverage of home-based newborn care, assessed on eight indicators, increased from $48.5 \%$ in 1995 - 96 to $87.1 \%$ in 2006 - 08. The proportion of women with any maternal health conditions during pregnancy reduced by $44.76 \%(P<0.001)$, during labor by $44.59 \%(\mathrm{P}<0.001)$ and during the postpartum period by $77.82 \%(P<0.001)$. The mean number of maternal conditions per 100 women reduced by $69 \%(P<0.001)$. The need for emergency obstetric care was reduced by $78.83 \%(\mathrm{P}<0.001)$. The proportion of women free of any maternal health condition increased from $32.9 \%$ to $64.6 \%$.
\end{abstract}

\section{Conclusions}

Home-based neonatal care interventions were associated with a significant reduction in the incidence of maternal health conditions. Developing a dedicated package of home-based maternal care in combination with neonatal care may further improve maternal health.

Maternal morbidities constitute a significant burden than maternal mortality in developing countries. Community-based estimates of maternal morbidity in developing countries ranges from 16.5 pregnancy-related complications to more than 100 acute complications for every maternal death. ${ }^{1,2}$ Nevertheless, as most of the community-based estimates of maternal morbidities were based only on recall by women, the validity of the estimates was questionable. ${ }^{3-5}$ We had reported one of the first prospectively mea- sured community-based estimates of maternal morbidities in women who had delivered at home from rural Gadchiroli, India. These observations in which the incidence of maternal morbidities during labor and puerperium was $52.6 \%$ (17.7\% during labor and $42.0 \%$ during puerperium) were from the first year (1995-96) of the field trial of homebased newborn care (HBNC) in Gadchiroli. ${ }^{6}$ In the third year (1997-98) of the trial, newborn mortality rate (NMR), which was the primary outcome of the trial, decreased by $62 \%$ in 
comparison to the control area. ${ }^{7}$ Hence the HBNC interventions were continued as a service program in the 39 villages uninterruptedly since then, further reducing the NMR and the infant mortality rate (IMR) to 25.2 and 31.1 respectively by $2001-03 .^{8}$

To study whether these interventions also impacted maternal health, specifically adverse maternal health conditions, we analyzed the data from the Gadchiroli field trial and the subsequent service program in 39 intervention villages from 1995 - 96 to 2008 with the objective a) to evaluate the association between HBNC interventions and the incidence of maternal health conditions including the need for emergency obstetric care and $b$ ) to estimate the longitudinal trend of the incidence of maternal health conditions in 39 villages.

\section{METHODS}

\section{AREA AND POPULATION}

The field trial of HBNC was conducted in the Gadchiroli district in Maharashtra state in India during 1993-98 by SEARCH (Society for Education, Action, and Research in Community Health). ${ }^{9}$ The area (figure 1), population characteristics, prevailing healthcare, the background work of SEARCH, the methods of data collection, the quality and the validation of the data, the definitions, and the incidence of maternal health condition during the first year of the intervention (1995-96) have all been extensively reported. 6,7,10

Since traditional birth attendants (TBAs) used to conduct most deliveries in rural Gadchiroli at home, SEARCH had trained the TBAs in the area in 1988-89, including those in the 39 intervention villages. They were trained to distribute iron-folic acid and calcium tablets during pregnancy, provide vitamin A supplements if a woman complained of night blindness in the last trimester, and use gentian violet to treat vaginal discharge. They were also trained in handwashing; using gloves, antiseptic lotion, clean blade and thread during delivery; the importance of antenatal checkups and early referral when certain danger signs were present. ${ }^{11}$

The sources of maternal health care were the clinic of SEARCH located outside the intervention villages, run by an obstetrician (RB), the government district hospital located in the centre of the intervention area and few private doctors. The families used to call on unqualified private practitioners to inject oxytocin to expedite home deliveries.

\section{INTERVENTIONS}

In the first year of the intervention phase (1995-96) of the field trial of HBNC 39 female community health workers (CHWs) were introduced, one in each intervention village. These were married women residents of the village with 5 to 10 years of schooling. Their training and job description in the first year of the trial has been described in detail. $7,9,10,12-14$

After the maternal and neonatal conditions were prospectively observed and recorded in the first year of the field trial, 6,12 the CHWs were trained and home-based newborn care interventions were incrementally introduced. ${ }^{7}$ In the third and final year of the trial (1997-98) and subse-

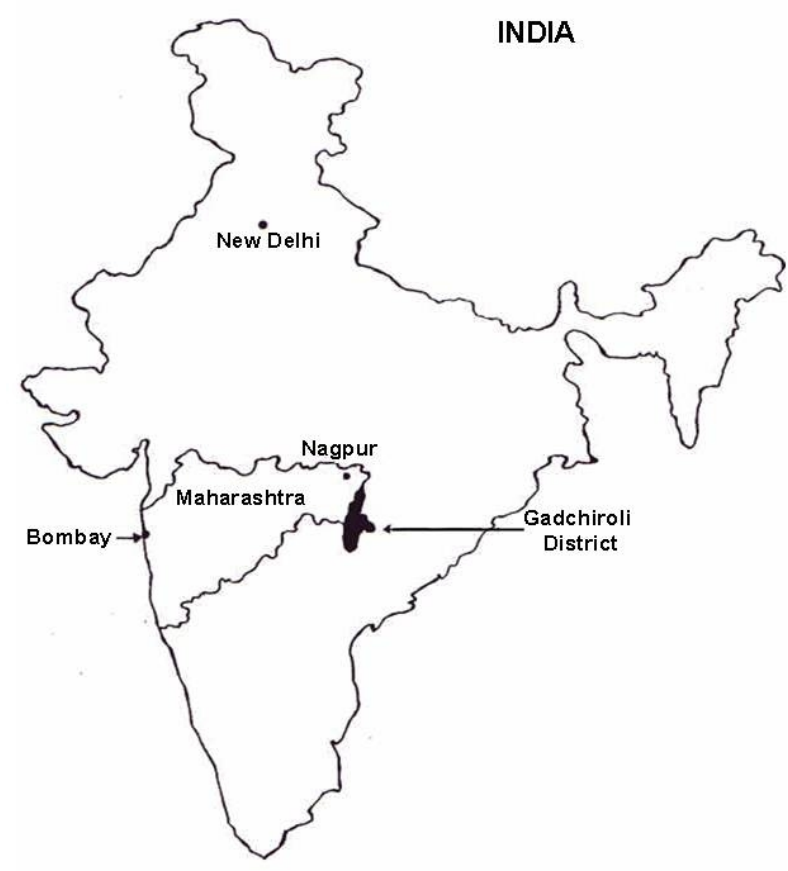

Figure 1. India, Maharashtra, Gadchiroli

quently, during the service program (1998 - 2008), CHWs provided the interventions described in Panel 1. The CHWs were part-time workers of SEARCH, and their payment was based on a mix of fixed payment (1/3) and performancebased evaluation $(2 / 3)$.

CHWs worked in close collaboration with the family, TBA and supervisory physician (SB), and later with the two field supervisors who were upgraded CHWs. The supervisors visited each village once every 15 days to check the findings and the quality of interventions of the CHW, but the supervisors themselves did not provide any treatment directly.

The clinic of SEARCH, located outside the intervention area, provided the facilities for an antenatal checkup; detection of risk factors; management of anemia, medical illnesses and reproductive tract infections; and, especially in the case of risk factors, advising the mothers to seek hospital delivery, usually at the government district hospital which was the only source of caesarian section delivery and blood transfusion. SEARCH as well as the government hospital provided free or subsidized ambulance service.

\section{MATERNAL KNOWLEDGE AND PRACTICES}

We had studied maternal knowledge and practices through key informant interviews (with TBAs) and focused group discussions with mothers and grandmothers during the preintervention period. ${ }^{15}$ These had revealed the following harmful beliefs and behaviors: 1) A mother should not eat adequately during pregnancy or consume iron tablets, lest a large fetus would lead to a difficult delivery. 2) Pregnant women should not consume meat, milk, eggs ('hot foods') or certain leafy vegetables or fruits ('papaya' may cause abortion, guava or banana may cause 'cough'). 3) Pregnancy and delivery are natural events, hence there is no need for 
medical checkups or interventions. 4) Breast feeding was often not started before the third day. This is because the colostrum was considered impure milk and hence discarded. 5) Delivery rooms were dirty and without toilet facilities. 6) A mother could not step out of the delivery room for five to seven days after delivery. 7) To minimize their toilet needs during this period, mothers reduced their food and fluid intake.

\section{Panel 1. Interventions in Home Based Newborn Care}

1. Keeping a list of women who could become pregnant and registering pregnancy in the fourth or fifth month of pregnancy.

2. Making three home visits during pregnancy to collect information about maternal health and giving appropriate advice for seeking care from a TBA or doctor. If necessary, they would accompany the woman to a medical clinic.

3. Giving health education - to individual women twice during pregnancy, by using a flip chart which gave messages about diet, care during pregnancy, antenatal checkup, iron-folic acid supplements, tetanus toxoid, night blindness, birth preparedness, danger signs during pregnancy, delivery and postpartum period and seeking medical care, safe home delivery, breastfeeding and the care of newborns.

4. Being present at home delivery, to observe the TBA conducting the delivery, to assist her and to encourage her to follow the instructions about safe and clean delivery and to record the events and timings.

5. Recommending referral when necessary and helping the family make the proper decision.

6. Providing care to the newborn immediately at birth.

7. Examining the newborn and mother on the first day within 6 hours after birth.

8. Encouraging early and exclusive breastfeeding.

9. Revisiting the baby and the mother on days $2,3,5,7,15,21,28$. During these home visits she inquired about the presence of certain complaints, examined mother and newborn, gave health education to the mother using a flipchart, helped the mother in breastfeeding and in keeping the baby warm, managed newborn sicknesses and advised referral when necessary.

10. In addition to treating sicknesses in newborns and pneumonia in under-five year children, she also treated minor illnesses in children and adults.
These insights were used to design the health education messages imparted by the CHWs at home using a flip chart, twice during pregnancy and once during the newborn / postpartum period. Additionally, group health education for pregnant women and mothers-in-law was organized in the village every four months. The CHW interviewed the mothers using a questionnaire to assess their knowledge fifteen days after the group health education session. CHW also observed the mothers' health behaviors and had recorded the same in a printed mother- newborn record during her home visits.

\section{STATISTICAL ANALYSIS}

The definitions used to diagnose maternal health conditions in this field setting are in Panel 2 and have also been published earlier. $^{6}$

Some women used to move temporarily to their parents' home for delivery. We included the events in the village where they actually occurred ('de-facto method') irrespective of where the women came from. The total number of deliveries, stillbirths (completed 28 weeks of gestation) and child deaths in the intervention and control villages were regularly recorded by an independent system of vital statistics collection using male community health workers. This system has been operational since 1988. Recording of adult deaths, including maternal deaths, was not part of the vital statistics collection system. This system had been assessed to be $98 \%$ complete. ${ }^{12}$ The proportion of mothers and deliveries observed (coverage) by female CHW and included in this study was estimated by comparing them with these vital statistics data on total deliveries in the area. Percent difference was calculated by dividing the absolute difference for that variable by percent incidence of that variable in the first year.

In table 2 (interventions), the mean percent coverage was calculated by calculating the mean of coverage of all eight indicators for each year. In Tables $\underline{3}, \underline{4}$ and $\underline{5}$, the data collection for certain conditions was started at a later period than the baseline, and the denominator was taken accordingly. Data collection on the prolonged rupture of membranes and abnormal behavior was stopped in the years 1998 - 2002, and was restarted immediately after. The abnormal presentation was recorded in home deliveries only when the CHW was present at the time of delivery.

Data of two successive years were combined to increase the robustness of the data except for the $1^{\text {st }}$ year of the data collection $(1995$ - 96), which was considered the baseline period for this analysis. Significance was calculated on the basis of percent reduction. $P$ value for overall change from 1995 to 2008 was calculated using Chi-square test. Analysis was done using statistical package $\mathrm{R}$ (version 3.6.2). 


\section{Panel 2. Definitions of maternal health condition}

1. Edema: Bipedal edema observed by CHW in last trimester.

2. Vaginal discharge: Excessive and abnormal vaginal discharge as perceived by woman in last trimester.

3. Night blindness: Reported by woman using a very specific local term, "Chalanyaandhar" in last trimester.

4. Fever: History of fever in the last week before delivery in last trimester.

5. Skin infection: Boil, ulcer, pustule, abscess, pyoderma in last trimester.

6. Itching of Skin: Infected scabies, itching on body in last trimester

7. Burning of urine: History of burning of urine in last 24 hours in last trimester

8. Antepartum hemorrhage: Vaginal bleeding/ spotting in last trimester

9. Prolonged rupture of membranes: more than 24 hours between loss of water and onset of labor pain [excluding caesarian cases]

10. Abnormal presentation: Presenting part during delivery being face, hand, shoulder, leg or breech (in presence of $\mathrm{CHW}$ ).

11. Retained placenta: Placenta did not come out for more than one hour after baby's birth [excluding caesarian cases]

12. Primary postpartum hemorrhage (PPH): Excessive bleeding on first day (as above) and an objective evidence of circulatory stress, either mother hypothermic $\left(35.0^{\circ} \mathrm{C}\right)$ or unconscious.

13. Secondary postpartum hemorrhage: five days after delivery, mother used more than five pads a day or increased vaginal bleeding after bleeding had decreased or stopped; or any increase in use of pads (by at least 2) after it was less or none.

14. Puerperal fever: Temperature $>37.8^{\circ} \mathrm{C}$ on any day during 2-28 days after delivery.

15. Puerperal Infection of genital tract: Foul smelling vaginal discharge and fever; or foul smelling vaginal discharge and secondary $\mathrm{PPH}$.

16. Fits: Mother had convulsions during or after labor on any day within a month after delivery.

17. Abnormal behavior: Abnormal speech or behavior on any day within a month after delivery.
18. Insomnia: Inability to sleep but behavior is normal on any day within a month after delivery.

19. Breast problems: Retracted or cracked nipple (day one); or painful lumps in breast after delivery; or difficulties in breastfeeding on any day within a month after delivery.

20. Need of emergency obstetric care: Presence of any one of the following
a) Primary $\mathrm{PPH}$
b) Retained placenta
c) Fits

21. Need of medical attention (non-emergency): Presence of any one of the following
a) Abnormal presentation
b) Puerperal infection
c) Abnormal behavior
d) Secondary PPH
e) Breast problems with fever

\section{RESULTS}

The characteristics of the mothers studied, their place of delivery, the source of obstetrical care and the change from 1995 - 96 to 2006 - 2008 are described in Table 1. A total of 10780 deliveries took place over 13 years in the 39 villages, out of which 10208 (94.7\%) deliveries were observed. Similarly, a total of 10208 mothers were observed and served over 13 years. The proportion of literate mothers increased significantly by $135 \%$, from $39.1 \%$ to $92.1 \%$. The mean parity decreased from 1.5 to 0.7 , as well as the percentage of multi-parous women (parity more than 3). The mean age of first pregnancy decreased from 23.9 years to 22.4 years. The proportion of women with past history of stillbirth or newborn death reduced significantly by $44.55 \%$. The proportion of home deliveries decreased by $27.75 \%$, whereas the proportion of institutional deliveries increased from $5.2 \%$ to $31.2 \%$. The proportion of the deliveries attended by TBA reduced by $22.61 \%$, whereas the proportion of deliveries conducted by Nurse / Doctor increased by $137.5 \%$. The rate of caesarian section deliveries increased significantly from $0.5 \%$ at the baseline to $7.3 \%$ in $2006-08$. The proportion of home deliveries involving visits of a local medical practitioner, usually untrained, remained almost the same. Nevertheless, as the overall proportion of home deliveries decreased significantly, the proportion of deliveries attended by local medical practitioners probably increased. 
Table 1. Characteristics of Women and the Sources of Obstetrical Care in Community Based Program of Rural Gadchiroli $(1995-2008, n=10208 * *)$

\begin{tabular}{|c|c|c|c|c|c|c|}
\hline \multirow[t]{2}{*}{ Characteristics } & $\begin{array}{l}1995-96 \\
(n=772)\end{array}$ & $\begin{array}{l}1996-98 \\
(n=1631) \\
\end{array}$ & $\begin{array}{c}1998-2006 \\
(n=6265)\end{array}$ & $\begin{array}{l}2006-08 \\
(n=1540) \\
\end{array}$ & \multirow[t]{2}{*}{$\begin{array}{l}\text { Absolute change in percentage point } \\
\text { (1995-96 vs 2006-08) }\end{array}$} & \multirow[t]{2}{*}{$\begin{array}{l}\text { P value for overall } \\
\text { change }\end{array}$} \\
\hline & $\%$ & $\%$ & $\%$ & $\%$ & & \\
\hline Age years, mean (SD) & $23.9(4.60)$ & $23.8(4.02)$ & $23.11(3.40)$ & $22.41(2.91)$ & & $<0.001$ \\
\hline Literate women (percent) & 39.1 & 43.2 & 69.9 & 92.1 & 53.02 & $<0.001$ \\
\hline \multicolumn{7}{|l|}{ Parity } \\
\hline Primiparous & 30.1 & 30.5 & 39.0 & 46.9 & 16.83 & $<0.001$ \\
\hline $1-3$ & 61.3 & 63.0 & 58.0 & 52.7 & -8.61 & $<0.001$ \\
\hline More than 3 & 8.7 & 6.6 & 3.0 & 0.5 & -8.22 & $<0.001$ \\
\hline Mean Parity (SD) & $1.52(1.48)$ & $1.28(1.31)$ & $0.97(1.1)$ & $0.72(0.84)$ & & $<0.001$ \\
\hline $\begin{array}{l}\text { Past history of still birth or neonatal } \\
\text { death }\end{array}$ & 17.1 & 17.5 & 13.6 & 9.5 & -7.62 & $<0.001$ \\
\hline \multicolumn{7}{|l|}{ Place of delivery } \\
\hline Home & 94.8 & 96.2 & 81.9 & 68.5 & -26.31 & $<0.001$ \\
\hline Facility delivery & 5.2 & 3.7 & 18.1 & 31.2 & 26.05 & $<0.001$ \\
\hline On the way to hospital & 0.0 & 0.0 & 0.0 & 0.3 & 0.26 & 0.0296 \\
\hline Missing & 0.0 & 0.1 & 0.0 & 0.0 & 0.00 & 0.5948 \\
\hline \multicolumn{7}{|l|}{$\begin{array}{l}\text { Who conducted delivery (exclusive } \\
\text { categories) }\end{array}$} \\
\hline TBA & 88.2 & 94.3 & 83.6 & 68.2 & -20.03 & $<0.001$ \\
\hline Relatives & 3.9 & 1.4 & 1.6 & 2.6 & -1.29 & 0.0003 \\
\hline Nurse / doctor\# & 7.9 & 4.0 & 9.1 & 18.8 & 10.86 & $<0.001$ \\
\hline TBA + Nurse/doc & 0.0 & 0.0 & 5.1 & 8.4 & 8.44 & $<0.001$ \\
\hline $\mathrm{CHW}$ & 0.0 & 0.1 & 0.6 & 1.9 & 1.95 & $<0.001$ \\
\hline Missing information & 0.0 & 0.2 & 0.0 & 0.1 & 0.06 & 0.3547 \\
\hline Caesarian section delivery. & 0.5 & 0.7 & 3.8 & 7.3 & 6.82 & $<0.001$ \\
\hline Doctors visit at home during labor $\$$ & 27.3 & 25.1 & 28.4 & 27.1 & -0.25 & 0.0003 \\
\hline
\end{tabular}

All incidence are calculated for all mothers excluding twin births

\# Including home and hospital deliveries. Those visiting during home deliveries are usually unqualified medical practitioners

$\$$ Doctors visited home for any complication / problem during labor

**: $\mathrm{n}$ based on all years between 1995 and 2008 . 
The coverage of HBNC interventions on eight selected indicators is described in Table 2. The coverage according to each of the eight indicators, as well as the mean coverage increased progressively and significantly from the first to the third year (1997 - 98) and then was maintained subsequently throughout the period of the continued service program. The increase in the coverage was the steepest during the years of trial, reaching saturation point during the service program. The antenatal medical consultation seeking increased during the second and third year of the trial and subsequently from $2002-04$. The proportion of women visited by the CHW increased from 74.2 in 1995 - 96, reaching 89.2 by the end of the trial (1997 - 98), and peaking by 1998 - 2000, after which it remained around the same level. Health education was introduced only in the third year of trial and had continued later on.

The incidence of maternal health conditions during the last trimester of pregnancy, the change over time and the mean number of maternal health conditions per 100 mothers is shown in Table 3 . There was a significant reduction in swelling on feet, excessive vaginal discharge, night blindness, fever, and burning in urine. No significant difference was observed in the incidence of skin infection, itching of the skin and ante-partum hemorrhage. Nevertheless, the incidence of these conditions was minuscule. Overall during pregnancy, the maximum percentage reduction was observed in night blindness (88.4\%), followed by excessive vaginal discharge $(87.34 \%)$, while the least reduction was observed in swelling over feet (32.97\%). The proportion of mothers with any adverse maternal health condition during pregnancy reduced by $44.76 \%$, while the mean number of conditions per 100 mothers reduced from 51 in 1995 - 96 to 26 in 2006 - 08, a total reduction of $49 \%$.

The incidence of maternal health conditions during labor, the difference over time and the mean number of maternal health conditions per 100 mothers are shown in Table 4. During labor, the incidence of primary postpartum hemorrhage (the most, by $87.47 \%$ ), abnormal presentation and retained placenta reduced significantly. There was no reduction in the incidence of prolonged rupture of membranes (PROM). Overall, the proportion of women with any adverse maternal health condition during labor decreased from $12.31 \%$ to $6.82 \%$, a reduction of $44.59 \%$. Similarly, the mean number of maternal health conditions per 100 mothers decreased from 13 to 7 , a reduction of $46 \%$.

The incidence of maternal health conditions during postpartum period, totally during pregnancy, labor and postpartum, the change over time, as well as the mean number of maternal health conditions per 100 mothers, are shown in Table 5. During puerperium, the incidence of most of the adverse maternal health conditions, namely secondary postpartum hemorrhage ( $\mathrm{PPH}$ ), puerperal fever, suspected puerperal infection, fits during puerperium, insomnia, breast problems and skin infection reduced significantly. Although the incidence of abnormal behavior did not reduce significantly, it was present in a very small proportion of women, $0.26 \%$ in 1995 - 96 and 0.06 in $2006-08$. The maternal health conditions with the highest incidence at the baseline were breast problems (18.39\%), secondary PPH (15.16\%), puerperal fever (12.05\%) and suspected puerperal infection $(8.42 \%)$, all of which demonstrated significant re- duction of $73.17 \%, 86.29 \%$, $88.68 \%$ and $100 \%$ respectively. Overall, the proportion of mothers with any adverse maternal health condition during puerperium reduced by $77.82 \%$ and the mean number of conditions per 100 mothers reduced from 74 in 1995 - 96 to 11 in 2006 - 08, a total reduction of $85 \%$.

Overall, the mean number of adverse maternal health conditions per 100 mothers during pregnancy, labor and puerperium decreased from 140 in 1995 - 96 to 44, a total reduction of $69 \%$. The proportion of women with any adverse maternal health condition during pregnancy, labor and puerperium decreased from 67.1 to 35.39 , a $42.26 \%$ reduction. Additionally, we had classified the primary $\mathrm{PPH}$, retained placenta and fits as maternal health conditions requiring emergency obstetric care. The total incidence of these conditions decreased significantly by $78.83 \%$.

After the health education was introduced in the third year of interventions, many women demonstrated correct knowledge and behaviors relevant to maternal health commensurate with the health education messages delivered. For example, when questioned, $84.4 \%$ of mothers responded that they should eat adequately during pregnancy and in the postpartum period, $78.7 \%$ responded that the family should make preparations for delivery, $84.4 \%$ said that hand washing is necessary during delivery and during baby care, and $85 \%$ told that the delivery room should be clean.

Mothers' self-reported behavior showed that 93.9\% mothers ate adequately during pregnancy, 39.1\% sought antenatal/medical care during pregnancy, $11.8 \%$ consumed iron/calcium tablets during the last trimester of pregnancy and $78.9 \%$ ate adequately after delivery*. The $\mathrm{CHW}$ also observed that the delivery room was clean in $75.8 \%$ deliveries.

\section{DISCUSSION}

This analysis showed that when the trained CHWs provided home-based newborn care interventions in 39 intervention villages over 13 years, various adverse maternal health conditions during pregnancy, labor and puerperium decreased significantly. The reduction was broad, occurring in most of the conditions, including night blindness, vaginal discharge, fever, suspected puerperal infections, primary and secondary postpartum hemorrhage, breast problems, and insomnia. Moreover, the need for emergency obstetric care as well as non-emergency medical attention also decreased significantly.

Was the diagnosis of maternal health conditions valid? Due to the inherent limitations of the setting, the home deliveries and the postpartum period were not completely witnessed by a physician or accompanied by laboratory tests. The observations on the health of the mothers were recorded by the CHWs, and the quality of their data was regularly checked by a visiting physician. As reported earlier, their data showed $94.8 \%$ agreement with the parallel data collected by the physician on 18 maternal variables in a subsample. ${ }^{6}$ Similarly, the diagnosis was made by a computer program using certain defined criteria as described in Panel $\underline{2}$, and the same criteria were consistently applied over the entire thirteen years period. 
Table 2. Maternal Care Interventions and their Percent Coverage during Different Years of Trial and Service Program (1995-2008, $\left.\mathrm{n}=10208^{* * *}\right)$

\begin{tabular}{|c|c|c|c|c|c|c|c|}
\hline & & \multirow{2}{*}{$\begin{array}{c}\begin{array}{c}1995-96 \\
(\mathrm{n}=772)\end{array} \\
\%\end{array}$} & \multirow{2}{*}{$\begin{array}{c}\begin{array}{c}1996-98 \\
(\mathrm{n}=1631)\end{array} \\
\%\end{array}$} & \multirow{2}{*}{$\begin{array}{c}\begin{array}{c}1998-2006 \\
(\mathrm{n}=6265)\end{array} \\
\%\end{array}$} & \multirow{2}{*}{$\begin{array}{c}\begin{array}{c}2006-08 \\
(n=1540)\end{array} \\
\% \\
\text { incidence }\end{array}$} & \multirow{2}{*}{$\begin{array}{l}\text { Absolute change in percentage } \\
\text { point (1995-96 vs 2006-08) }\end{array}$} & \multirow{2}{*}{$\begin{array}{l}\text { P value for } \\
\text { overall } \\
\text { change }\end{array}$} \\
\hline & & & & & & & \\
\hline \multicolumn{8}{|c|}{ Selected indicators of the interventions } \\
\hline \multirow[t]{3}{*}{ A } & $\begin{array}{l}\text { 1. Tetanus toxoid received at least once (out } \\
\text { of three) during pregnancy. }\end{array}$ & 79.0 & 95.5 & 98.7 & 99.5 & 20.5 & $<0.001$ \\
\hline & 2. Seen by doctor during pregnancy & 14.0 & 25.3 & 49.7 & 40.5 & 26.5 & $<0.001$ \\
\hline & $\begin{array}{l}\text { 3. Percent deliveries at home conducted by } \\
\text { trained TBA }\end{array}$ & 85.7 & 97.1 & 95.9 & 95.7 & 5.8 & $<0.001$ \\
\hline \multirow[t]{2}{*}{ B } & 4. Home visits and observation by $\mathrm{CHW}$ & 74.2 & 89.2 & 99.2 & 99.5 & 25.5 & $<0.001$ \\
\hline & $\begin{array}{l}\text { 5. CHW present at the time of delivery at } \\
\text { home }\end{array}$ & 77.6 & 79.7 & 85.2 & 84.5 & 8.0 & $<0.001$ \\
\hline \multirow[t]{2}{*}{ C } & $\begin{array}{l}\text { 6. Exclusive breast feeding started within } 6 \\
\text { hours (excluding caesarian cases) }\end{array}$ & 57.7 & 87.8 & 95.7 & 98.8 & 38.4 & $<0.001$ \\
\hline & $\begin{array}{l}\text { 7. CHW advised and assisted mother in } \\
\text { newborn care at home }\end{array}$ & - & 89.2 & 99.2 & 99.5 & 10.5 & $<0.001$ \\
\hline D & $\begin{array}{l}\text { 8. Health education at least twice by home } \\
\text { visits. }\end{array}$ & NR & NR & 81.7 & 84.8 & 18.7 & $<0.001$ \\
\hline \multicolumn{2}{|c|}{ Mean percent coverage on the 8 indicators } & 48.5 & 70.5 & 86.2 & 87.1 & 38.6 & $<0.001$ \\
\hline
\end{tabular}

All incidence are calculated for all mothers excluding twin births

NR : Not Recorded

*** $\mathrm{n}$ based on all years between 1995 and 2008 
Table 3. Incidence of Maternal health conditions during Pregnancy in rural Gadchiroli (1995-2008, $\left.n=10208^{* * *}\right)$

\begin{tabular}{|c|c|c|c|c|c|c|}
\hline \multirow[t]{2}{*}{$\begin{array}{l}\text { Type of maternal health } \\
\text { condition }\end{array}$} & $\begin{array}{c}1995-96 \\
(n=772)\end{array}$ & $\begin{array}{c}1996-98 \\
(n=1631)\end{array}$ & $\begin{array}{c}1998-06 \\
(n=6265)\end{array}$ & $\begin{array}{l}2006-08 \\
(n=1540)\end{array}$ & \multirow[t]{2}{*}{$\begin{array}{l}\text { Absolute change in percentage point } \\
(1995-96 \text { vs 2006-08) }\end{array}$} & \multirow[t]{2}{*}{$\begin{array}{l}\text { P value for overall } \\
\text { change }\end{array}$} \\
\hline & $\%$ & $\%$ & $\%$ & $\%$ & & \\
\hline Swelling on feet & 23.1 & 20.8 & 18.0 & 15.5 & -7.6 & $<0.001$ \\
\hline Excessive vaginal discharge. & 12.3 & 9.3 & 3.6 & 1.6 & -10.7 & $<0.001$ \\
\hline Night blindness. & 8.8 & 7.2 & 3.5 & 1.0 & -7.8 & $<0.001$ \\
\hline Fever & 7.0 & 6.1 & 3.0 & 2.6 & -4.4 & $<0.001$ \\
\hline Skin infection* & NA & NA & 0.5 & 0.5 & -0.2 & 0.2621 \\
\hline Itching of skin* & NA & NA & 2.4 & 3.3 & 0.9 & 0.2405 \\
\hline Burning in urine\# & NA & NA & 2.1 & 1.2 & -2.0 & 0.0050 \\
\hline $\begin{array}{l}\text { Antepartum hemorrhage } \\
\text { (APH)\# }\end{array}$ & NA & NA & 0.3 & 0.4 & 0.1 & 0.9319 \\
\hline $\begin{array}{l}\text { Any condition during } \\
\text { pregnancy }\end{array}$ & 40.7 & 34.8 & 25.7 & 22.5 & -18.2 & $<0.001$ \\
\hline $\begin{array}{l}\text { Mean no. of conditions per } \\
100 \text { mother }\end{array}$ & 51 & 43 & 31 & 26 & -25.0 & $<0.001$ \\
\hline
\end{tabular}

All incidence are calculated for all mothers excluding twin births

* : Starting year is 2002-03

\# : Starting year is 2001-02

NR: Not Recorded

*** $\mathrm{n}$ based on all years between 1995 and 2008 
Table 4. Incidence of Maternal health conditions during Labor in Rural Gadchiroli (1995-2008, $\left.n=10208^{* *}\right)$

\begin{tabular}{|c|c|c|c|c|c|c|}
\hline \multirow[t]{2}{*}{ Type of maternal health condition } & $\begin{array}{l}1995-96 \\
(n=772)\end{array}$ & $\begin{array}{l}1996-98 \\
(n=1631)\end{array}$ & $\begin{array}{l}1998-06 \\
(n=6265)\end{array}$ & $\begin{array}{l}2006-08 \\
(n=1540)\end{array}$ & \multirow{2}{*}{$\begin{array}{l}\text { Absolute change in percentage } \\
\text { point (1995-96 vs 2006-08) }\end{array}$} & \multirow{2}{*}{$\begin{array}{c}\text { P value for } \\
\text { overall } \\
\text { change }\end{array}$} \\
\hline & $\%$ & $\%$ & $\%$ & $\%$ & & \\
\hline Prolonged rupture of membranes & 5.2 & 4.7 & 4.4 & 4.5 & -0.7 & 0.9162 \\
\hline Prolonged labor & 9.8 & 7.9 & 20.1 & 17.9 & 8.1 & $<0.001$ \\
\hline Abnormal presentation $\$$ & 4.2 & 2.0 & 2.2 & 2.3 & -1.9 & $<0.001$ \\
\hline Retained placenta & 1.8 & 2.1 & 0.6 & 0.9 & -0.9 & $<0.001$ \\
\hline Primary post-partum hemorrhage & 3.1 & 1.4 & 0.8 & 0.4 & -2.7 & $<0.001$ \\
\hline Any Maternal health condition during labor & 16.8 & 13.1 & 11.2 & 18.4 & 1.6 & $<0.001$ \\
\hline $\begin{array}{l}\text { Any Maternal health condition during labor } \\
\text { (excluding Prolonged labor) }\end{array}$ & 12.3 & 9.3 & 5.3 & 6.8 & -5.5 & $<0.001$ \\
\hline $\begin{array}{l}\text { Mean no. of maternal health conditions per } 100 \\
\text { mother }\end{array}$ & 23 & 15 & 15 & 24 & 1.0 & 0.7695 \\
\hline $\begin{array}{l}\text { Mean no. of maternal health conditions per } 100 \\
\text { mother (excluding Prolonged labor) }\end{array}$ & 13 & 10 & 6 & 7 & -6.0 & $<0.001$ \\
\hline $\begin{array}{l}\text { incidence are calculated for all mothers excluding twin births } \\
\text { Denominator is the deliveries where CHW is present } \\
\mathrm{n} \text { based on all years between } 1995 \text { and } 2008 \text {. }\end{array}$ & & & & & & \\
\hline
\end{tabular}


Table 5. Incidence of Maternal health conditions during Puerperium and Overall Period in Rural Gadchiroli (1995-2008, n=10208**)

\begin{tabular}{|c|c|c|c|c|c|c|}
\hline Type of maternal health condition & $\begin{array}{c}\begin{array}{c}1995-96 \\
(n=772)\end{array} \\
\%\end{array}$ & $\begin{array}{c}1996-98 \\
(n=1631) \\
\%\end{array}$ & $\begin{array}{c}1998-06 \\
(n=6265) \\
\%\end{array}$ & $\begin{array}{c}2006-08 \\
(n=1540) \\
\%\end{array}$ & $\begin{array}{l}\text { Absolute change in } \\
\text { percentage point } \\
\text { (1995-96 \& 2006-08) }\end{array}$ & $\begin{array}{c}\text { P value } \\
\text { for } \\
\text { overall } \\
\text { change }\end{array}$ \\
\hline \multicolumn{7}{|l|}{ During puerperium } \\
\hline Secondary postpartum hemorrhage & 15.2 & 9.9 & 2.5 & 2.1 & -13.1 & $<0.001$ \\
\hline Puerperal fever & 12.0 & 6.2 & 2.2 & 1.4 & -10.7 & $<0.001$ \\
\hline Suspected Puerperal infection & 8.4 & 3.8 & 0.5 & 0.0 & -8.4 & $<0.001$ \\
\hline Fits during puerperium & 1.2 & 0.6 & 0.1 & 0.0 & -1.2 & $<0.001$ \\
\hline Abnormal behavior & 0.3 & 0.4 & 0.3 & 0.1 & -0.2 & 0.5382 \\
\hline Insomnia & 7.4 & 3.1 & 2.6 & 2.3 & -5.0 & $<0.001$ \\
\hline Breast problems & 18.4 & 10.7 & 5.9 & 4.9 & -13.5 & $<0.001$ \\
\hline PNC- Skin infection & 2.2 & 1.1 & 0.8 & 0.5 & -1.7 & $<0.001$ \\
\hline Any condition during puerperium & 43.9 & 25.3 & 12.1 & 9.7 & -34.2 & $<0.001$ \\
\hline $\begin{array}{l}\text { Mean no. of maternal health conditions per } 100 \text { mother } \\
\text { during puerperium }\end{array}$ & 74 & 35 & 14 & 11 & -63.0 & $<0.001$ \\
\hline \multicolumn{7}{|l|}{ Overall } \\
\hline $\begin{array}{l}\text { Mean no. of maternal health conditions per } 100 \text { women } \\
\text { during pregnancy, labor and puerperium }\end{array}$ & 148 & 93 & 60 & 61 & -87.0 & $<0.001$ \\
\hline $\begin{array}{l}\text { Mean no. of maternal health conditions per } 100 \text { women } \\
\text { during pregnancy, labor and puerperium (excluding } \\
\text { Prolonged labor) }\end{array}$ & 140 & 89 & 45 & 44 & -96.0 & $<0.001$ \\
\hline $\begin{array}{l}\text { Any maternal health conditions during pregnancy, labor or } \\
\text { puerperium. }\end{array}$ & 70.1 & 56.0 & 42.3 & 41.3 & -28.8 & $<0.001$ \\
\hline $\begin{array}{l}\text { Any maternal health condition during pregnancy, labor or } \\
\text { puerperium (excluding Prolonged labor) }\end{array}$ & 67.1 & 54.9 & 36.4 & 35.4 & -31.7 & $<0.001$ \\
\hline Emergency maternal health conditions & 14.9 & 11.6 & 11.3 & 17.1 & 2.2 & $<0.001$ \\
\hline $\begin{array}{l}\text { Emergency maternal health conditions (excluding } \\
\text { Prolonged labor) }\end{array}$ & 5.8 & 4.0 & 2.8 & 1.2 & -4.6 & $<0.001$ \\
\hline Non-Emergency maternal health conditions & 21.6 & 13.7 & 4.5 & 4.0 & -17.7 & $<0.001$ \\
\hline
\end{tabular}

All incidence are calculated for all mothers excluding twin births

*** $\mathrm{n}$ based on all years between 1995 and 2008 
Many conditions, especially during pregnancy, or which require a physician's presence or laboratory investigations for diagnosis such as pregnancy-induced hypertension, preeclampsia, urinary tract infection, glycosuria and, proteinuria were not studied. Moreover, not all women who had delivered in these 39 villages were visited by the CHWs, especially during the first two years of the program, when the percentage coverage was 74.2 and 84.6 , respectively. The unstudied women may have had more health problems than in the women studied.

Can the observed reduction in maternal health conditions be attributed to the home-based newborn care? A major limitation of this evaluation was the lack of a control group. As stated above, the primary outcome of the Gadchiroli trial and the subsequent service program was not to assess the effect on maternal conditions (but newborn mortality), and hence these were not observed and recorded in the control area. In any event, in a community setting, it would have been difficult and unethical to observe and record health conditions without providing any intervention for thirteen years. The CHWs had observed and recorded maternal health conditions with minimum intervention in the first year and then with incremental homebased interventions in the second and third years of the trial as well as during the subsequent years of the service program. This allowed for the comparison of the incidence of maternal health conditions during the first and the last two years of interventions.

Another possible confounding is the change in the nature and availability of obstetrical care in the area over 13 years. There was a significant increase in institutional deliveries and caesarean section deliveries. In addition, the proportion of deliveries conducted by nurses or doctors and antenatal consultation by mothers increased significantly. Nevertheless, the maternal interventions of the HBNC itself may have significantly contributed to the change in the healthcare-seeking behavior of women leading to positive changes such as seeking antenatal medical consultation and seeking a referral for institutional delivery through better preparedness. Similarly, though there was an increase in institutional deliveries, this change mostly happened in the last 2 years, when the government launched the Janani Suraksha Yojana (JSY) and picked up.

Moreover, a very striking dose-response relationship was observed in the intervention area. The coverage of various interventions in the HBNC package progressively increased (table 2 and Fig. 2), with the mean percent score on eight indicators reaching $87.1 \%$ in $2006-08$ ( $p<0.001)$. The health condition burden per 100 women demonstrated a matching trend of reduction of $47.26 \%(\mathrm{p}<0.001)$ by $2006-08$ compared to the baseline. The primary outcome of the HBNC trial and service program, the newborn mortality rate, also decreased during these thirteen years from 62 in 1993 - 95 to $25.8(\mathrm{p}<0.005)$ in $2006-08$. Because of this strength of association and temporal relationship, it is reasonable to attribute the reduction in adverse maternal health conditions to HBNC.

Women's clinic and trained TBAs were in operation since 1988-89, and hence were part of the baseline scenario. Training of TBAs alone has not convincingly shown to reduce adverse maternal health conditions, but the knowl-

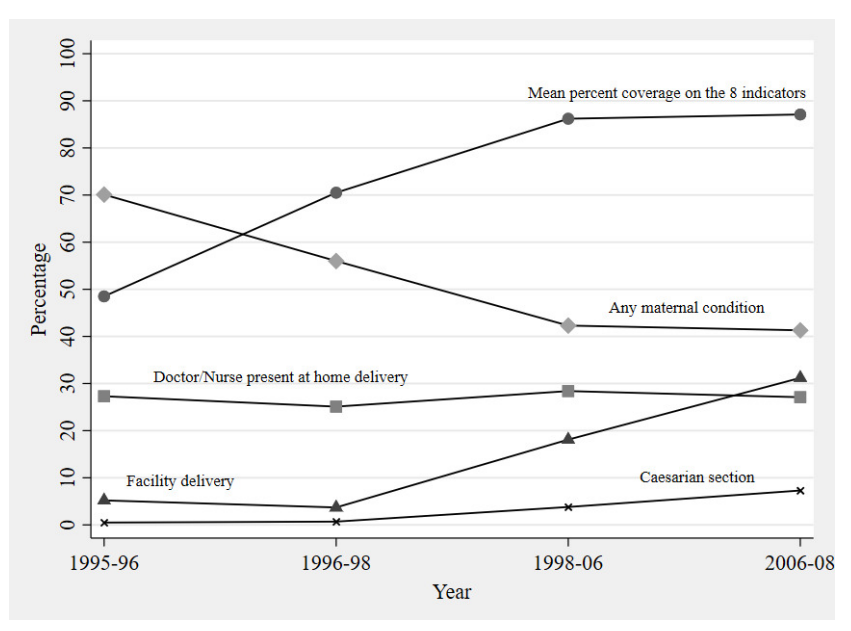

Figure 2. Home-based Newborn Care package showed progressively increasing coverage

edge of, and by a small degree, seeking referral for, has been found to have increased in a meta-analysis. ${ }^{16}$ An effect of larger degree is observed in our study, which can be attributed to the addition of a semi-skilled CHW to the pre-existing set-up of TBAs and the women's clinic. It might have contributed in the following ways:

1. Changed the maternal knowledge and behaviors. Another study from India has also shown that community-based behavior change management intervention for essential newborn care can significantly improve maternal health equity and outcomes including knowledge of danger signs, care practices, self-reported complications, and timely care-seeking from trained providers. ${ }^{17}$

2. Delivery and care practices of the TBAs are expected to have improved because an independent worker (CHW) now was observing and recording (Hawthorne effect).

3. Increased care seeking from a doctor during pregnancy, from $14 \%$ in $1995-96$ to $40.52 \%$ in $2006-08$ (table 2). Even one prenatal visit late in pregnancy has been shown to confer benefits. ${ }^{18}$

4. Early initiation of excusive breastfeeding (table 2).

5. Social and emotional support to mother due to the presence of a trained woman from her own village and culture. Studies in developed as well as developing countries have shown beneficial effects of a companion. ${ }^{19,20}$

The reduction in edema and night blindness could have occurred due to the changes in diet or increased care seeking during pregnancy due to health education. Reduction in vaginal discharge, infections and fever could be because of increased hand washing and better hygiene during delivery and the postpartum period or increased antenatal care seeking resulting in the treatment of reproductive tract infections. Considering that primary $\mathrm{PPH}$ is a major cause of maternal mortality, significant reduction observed in it is an important gain. It may have decreased due to better delivery practices by TBAs, institutional deliveries or due to initiation of early breast feeding (Fig. 2). Reduced PPH 
due to increased uterine contractions induced by early suckling is also plausible, though never proved by controlled trials. $^{21,22}$

Secondary PPH could have decreased due to reduced puerperal infections and increased breastfeeding. Social and emotional support as well as help in the management of newborn may have reduced the incidence of insomnia. Breast problems could have decreased due to heath education, support in breastfeeding and actively managing breastfeeding problems such as breast engorgement, cracked or inverted nipples or the inability of a premature/ septic newborn to suck. Earlier studies have shown that frequent home visits by a health worker improve breastfeeding. 5

A significant proportion of women in developing countries still deliver at home. Even those who deliver in hospitals are discharged within 24 to 48 hours. ${ }^{21}$ Thus, most women spend the postpartum period at home. The postpartum period remains a relatively neglected period though it contributed $61 \%$ of maternal deaths in developing countries $^{23}$ and has a high incidence, $43 \%$, of adverse maternal conditions. ${ }^{6}$ Some $23-50 \%$ of women perceive that they had health problems during this period, ${ }^{21}$ yet only a small proportion of women receive a postpartum home visit. The National Family Health Survey in India from 1998 - 99 had reported that only $17 \%$ of the home-delivered women received a postpartum visit by a health worker within two months of delivery. ${ }^{24}$

The WHO group on postpartum care had recommended that "since many births do take place outside the health system, caregivers at community level should be trained. Discharge from a health facility within 24 hours after birth with just one or two home visits may be hardly adequate". ${ }^{21} \mathrm{~A}$ Cochrane review focusing on the assessment of the effectiveness of community-based intervention packages in reducing maternal and newborn morbidity and mortality and improving neonatal outcomes also concluded that in addition to the importance of skilled delivery and facility-based services for maternal and newborn care, there is evidence to consider the integration of maternal and newborn care in community settings. This can allow several interventions to be packaged effectively for delivery through community health workers and health promotion groups. ${ }^{25}$

Our study supports these recommendations and shows that such an approach was associated with reduced maternal health conditions by $44.76 \%$ during pregnancy, $44.59 \%$ during labor and $77.82 \%$ during postpartum period. Homebased postpartum care and newborn care hence can neatly fit together.

\section{CONCLUSIONS}

It is generally believed that improving maternal care will improve newborn health as well. However, since the health and the health care of mother and baby are inseparable, it should not be surprising if this relationship operates in another way, improving newborn health care may improve maternal health. This study revealed such a phenomenon.

This is the first report of its kind, hence this cannot be considered a definitive answer. Though, as the adverse maternal health conditions decreased during pregnancy and postpartum period, this study should pave the way for more studies to confirm these findings. Even in the settings where significant mothers are delivering in institutions, as these mothers are discharged soon after the delivery, most of the postpartum /newborn period is spent at home. Hence an integrated package of home-based care for the mother and newborn is logical. Such a package can provide avenues for other health care actions such as the provision of birth planning through a continuum of care and therefore can be considered as an immediate possibility. In the specific context of India, where a large (more than 0.8 million) number of female community health workers are already functional in most of the states and providing home visits to the newborns as part of the national strategy of implementation of home-based newborn care, such possibility has concrete implications and immediate feasibility for national scaling up.

\section{ACKNOWLEDGEMENTS}

The authors would like to thank the women, traditional birth attendants, community health workers and the village community leaders in the 39 intervention villages as well as the communities of the 47 control villages. The study would have been impossible without them.

\section{ETHICAL APPROVAL}

This study analyses past data from the published trial of home-based newborn care (1995 - 98) and the subsequent service program continued by SEARCH. The services provided were completely free of cost and every beneficiary mother was explained all the interventions in vernacular language. Individual mother - newborn's identities are not revealed. SEARCH has kindly permitted the authors to use this data for publication.

\section{FUNDING}

Financial support for conducting the study was provided by The John D and Catherine T. MacArthur Foundation, Chicago, and The Ford Foundation, New Delhi. The funding sources had no involvement in the study.

\section{AUTHORSHIP CONTRIBUTIONS}

$\mathrm{AAB}$ analyzed the data and wrote the manuscript. ATB designed the study, trained the health workers, monitored the progress of the trial and reviewed the manuscript. RB trained the traditional birth attendants and reviewed the manuscript. MD monitored the data collection and did statistical analysis. KS did the statistical analysis. SB supervised the health workers in the field and provided field training/education. All authors have read and approved the final manuscript.

\section{COMPETING INTERESTS}

The authors completed the Unified Competing Interest form at http://www.icmje.org/disclosure-of-interest/ 
(available upon request from the corresponding author) and declare no conflicts of interest.

\section{CORRESPONDENCE TO:}

Abhay T Bang

search.gad@gmail.com

Society for Education, Action and Research in Community
Health (SEARCH), Shodhgram, Post-Chatgaon, TalukaDhanora, District-Gadchiroli, Maharashtra 442605, India

Submitted: August 05, 2021 GMT, Accepted: November 19, 2021 GMT 


\section{REFERENCES}

1. Datta KK, Shayma RS, Razack PMA, Ghosh TK, Arora RR. Morbidity pattern amongst rural women in Alwar, Rajasthan -- A cohort study. Health Population Perspective and Issues. 1980;3:282-292.

2. Koblinsky MA, Campbell OMR, Harlow SO. Mother and more: a broader perspective on women's health. In: Koblinsky M, Timyan J, Gay J, eds. The Health of Women: A Global Perspective. Westview Press; 1992.

3. Filippi V, Ronsmans C, Gandaho T, Graham W, Alihonou E, Santos P. Women's reports of severe (near-miss) obstetric complications in Benin. Stud Fam Plann. 2000;31(4):309-324. doi:10.1111/i.1728-4 465.2000.00309.x

4. Filippi V. Validation of women's perception of nearmiss obstetric morbidity in South Benin. Published online 1999.

5. Ransjo-Arvidson AB, Chintu K, Ng'andu N, et al. Maternal and infant health problems after normal childbirth: a randomised controlled study in Zambia. J Epidemiol Community Health. 1998;52(6):385-391. do $\mathrm{i}: 10.1136 / \mathrm{jech} \cdot 52.6 .385$

6. Bang RA, Bang AT, Reddy MH, Deshmukh MD, Baitule SB, Filippi V. Maternal morbidity during labor and puerperium in rural homes and the need for medical attention: A prospective observational study in Gadchiroli, India. British $J O B / G Y$.

2004;111(3):231-238. doi:10.1111/i.1471-0528.2004.0 0063.x

7. Bang AT, Bang RA, Baitule SB, Reddy MH, Deshmukh MD. Effect of home-based neonatal care and management of sepsis on neonatal mortality: field trial in rural India. Lancet. 1999;354(9194):1955-1961. doi:10.1016/s0140-6736(9 9)03046-9

8. Bang AT, Reddy HM, Deshmukh MD, Baitule SB, Bang RA. Neonatal and infant mortality in the ten years (1993 to 2003) of the Gadchiroli field trial: effect of home-based neonatal care. J Perinatol. 2005;25(1):S92-S107. doi:10.1038/sj.jp.7211277

9. Bang AT, Bang RA, Reddy HM, Deshmukh MD. Methods and the baseline situation in the field trial of home-based neonatal care in Gadchiroli, India. $J$ Perinatol. 2005;25(1):S11-S17. doi:10.1038/sj.jp.72112 $\underline{68}$

10. Bang AT, Bang RA. Background of the field trial of home-based neonatal care in Gadchiroli, India. J Perinatol. 2005;25(1):S3-S10. doi:10.1038/sj.jp.721126 $\underline{7}$
11. Bang RA, Bang AT, SEARCH team. Commentary on a community-based approach to reproductive health care. Int J Gynecol Obstet. 1989;30:125-129. do $\mathrm{i}: 10.1016 / 0020-7292(89) 90112-4$

12. Bang AT, Bang RA, Baitule S, Deshmukh M, Reddy $\mathrm{MH}$. Burden of morbidities and the unmet need for health care in rural neonates-a prospective observational study in Gadchiroli, India. Indian Pediatr. 2001;38:952-965.

13. Bang AT, Bang RA, Reddy HM. Home-based neonatal care: summary and applications of the field trial in rural Gadchiroli, India (1993 to 2003). J Perinatol. 2005;25(1):S108-S122. doi:10.1038/si.jp.721 $\underline{1278}$

14. Reddy MH, Bang AT. How to identify neonates at risk of death in rural India: clinical criteria for the risk approach. J Perinatol. 2005;25(1):S44-S50. doi:10.103 8/sj.jp.7211272

15. Bang RA, Bang AT. Perception of Rural Women on White Discharge. In: Gittleson J, ed. Listening to Women Talk about Their Health Issues: Evidence from India. Ford Foundation; 1994.

16. Sibley L, Sipe TA, Koblinsky M. Does traditional birth attendant training improve referral of women with obstetric complications: a review of the evidence. Social Science \& Medicine. 2004;59(8):1757-1768. doi:10.1016/j.socscimed.200 $\underline{4.02 .009}$

17. Kumar V, Kumar A, Das V, et al. Communitydriven impact of a newborn-focused behavioral intervention on maternal health in Shivgarh, India. International Journal of Gynecology \& Obstetrics. 2012;117(1):48-55. doi:10.1016/j.ijgo.2011.10.031

18. Vanneste AM, Ronsmans C, Chakraborty J, De Francisco A. Prenatal screening in rural Bangladesh: from prediction to care. Health policy and planning. 2000;15(1):1-10. doi:10.1093/heapol/15.1.1

19. Madi BC, Sandall J, Bennett R, MacLeod C. Effects of female relative support in labor: a randomized controlled trial. Birth. 1999;26(1):4-8. doi:10.1046/i.1 523-536x.1999.00004.x

20. Langer A, Campero L, Garcia C, Reynoso S. Effects of psychosocial support during labour and childbirth on breastfeeding, medical interventions, and mothers' wellbeing in a Mexican public hospital: a randomised clinical trial. BJOG. 1998;105(10):1056-1063. doi:10.1111/j.1471-0528.19 98.tb09936.x 
21. World Health Organization. Postpartum Care for the Mother and the Newborn: A Practical Guide. WHO; 1998.

22. Chua S, Arulkumaran S, Lim I, Selamat N, Ratnam SS. Influence of breastfeeding and nipple stimulation on postpartum uterine activity. Br J Obstet Gynecol. 1994;101:804-805.

23. Li XF, Fortney JA, Kotelchuck M, Glover LH. The postpartum period: the key to maternal mortality. International Journal of Gynecology \& Obstetrics. 1996;54(1):1-10. doi:10.1016/0020-7292(96)02667-7
24. National Family Health Survey, India. 1998-99; Key Findings. International Institute for Population Sciences; 2000.

25. Lassi ZS, Haider BA, Bhutta ZA. Communitybased intervention packages for reducing maternal and neonatal morbidity and mortality and improving neonatal outcomes. Cochrane Database of Systematic Reviews. 2010;(11):CD007754. doi:10.1002/1465185 8.cd007754.pub2 